\title{
Antimicrobial susceptibility and minimal inhibitory concentration of Pseudomonas aeruginosa isolated from septic ocular surface disease in different animal species
}

\author{
L. Leigue ${ }^{1,2, *}$, F. Montiani-Ferreira ${ }^{1}$ and B.A. Moore ${ }^{3}$ \\ ${ }^{I}$ Department of Veterinary Medicine, Universidade Federal do Paraná; Curitiba, PR, Brazil \\ ${ }^{2}$ Department of Microbiology, Institute of Biomedical Sciences, Universidade de São Paulo; São Paulo, SP, Brazil \\ ${ }^{3}$ Veterinary Specialty Hospital of San Diego, 10435 Sorrento Valley Road, San Diego, CA 92121, USA
}

\begin{abstract}
The purpose of this study was to evaluate the antibiotic susceptibility profile of Pseudomonas aeruginosa isolated from different animal species with septic ocular surface disease. Sixteen strains of $P$. aeruginosa were isolated from different species of animals (dog, cat, horse, penguin and brown bear) with ocular surface diseases such as conjunctivitis, keratocojnuctivits sicca and ulcerative keratitis. These isolates were tested against 11 different antimicrobials agents using the Kirby-Bauer disk-diffusion method. Minimum inhibitory concentrations (MICs) were determined using E-tests for two antibiotics (tobramycin and ciprofloxacin) commonly used in veterinary ophthalmology practice. Imipenem was the most effective antibiotic, with $100 \%$ of the strains being susceptible, followed by amikacin (87.5\%), gentamicin, norfloxacin, gatifloxacin and polymyxin (both with $81.5 \%$ of susceptibility). $\mathrm{MIC}_{90}$ of ciprofloxacin was $2 \mu \mathrm{g} / \mathrm{ml}$ and the values found ranged from $0.094 \mu \mathrm{g} / \mathrm{ml}$ to $32 \mu \mathrm{g} / \mathrm{ml}$. For tobramycin, $\mathrm{MIC}_{90}$ was $32 \mu \mathrm{g} / \mathrm{ml}$ and ranged from $0.25 \mu \mathrm{g} / \mathrm{ml}$ to $256 \mu \mathrm{g} / \mathrm{ml}$. The most effective in vitro antibiotic tested against $P$. aeruginosa in this study was imipenem, followed by amikacin. The $3 \mathrm{mg} / \mathrm{ml}$ eye drops commercially available ciprofloxacin presentations were in vitro effective against all strains tested in this study if applied up to 4 hours after instillation. Whereas for tobramycin the $3 \mathrm{mg} / \mathrm{ml}$ eye drops commercial presentations were not in vitro effective against some strains isolated in this study. Thus for ocular infections with $P$. aeruginosa when using tobramycin the ideal recommendation would be to either use eye drops with higher concentrations or decrease the frequency intervals from four to a minimum of every two hours.
\end{abstract}

Keywords: Antibiotic, Antimicrobial profile, Bacteria, Ocular infections.

\section{Introduction}

The eye is typically resistant to primary infection due to the numerous cellular and molecular elements that protect the corneal surface against microorganisms. These elements include tears, corneal nerves, the epithelium, keratocytes, polymorphonuclear cells, and cytokines (Akpek and Gottsch, 2003). The presence of tears is of particular importance since, besides preventing the cornea from drying, it also helps flush foreign particles from the ocular surface and transports antimicrobial proteins (lactoferrin, lysozyme, lipocalin, and beta-lysin) and immunoglobulins to the ocular surface to prevent infections (Mannis and Smolin, 1996). As a consequence of all these factors, with the exception of the herpesviruses and infection with Moraxella bovis, microorganisms cannot initiate primary keratitis in animals (Maggs, 2008).

Considering, septic ocular surface disease typically requires an initial injury, such as mechanical or chemical trauma, before a microorganism can infect the cornea (Mayo et al., 1986). Specifically, bacterial infections of ocular surfaces are commonly the result of a predisposing factor or disease that allows the overgrowth of a bacterium that is or is not a part of the ocular surface microbiota (Quinn et al., 1994; Moore et al. 1995; Ledbetter et al., 2009).

Pseudomonas aeruginosa, a gram-negative bacillus that is widely distributed in nature, is commonly considered a transitional opportunistic agent and part of the normal ocular surface microbiota (Quinn et al., 1994). However, P. aeruginosa is also frequently isolated from ocular surface infections, especially from ocular septic keratitis (Ledbetter et al., 2009). This microorganism is considered one of the most destructive bacteria associated with eye infections in any species (Gutierrez, 1972), having a variety of mechanisms and virulence factors which allow efficient colonization and subsequently compromised ocular tissues and most corneal layers. Examples of such factors include bacterial proteases, and an exotoxin that can destroy epithelial and endothelial cells within 24 hours.

Hemolysins also contribute to $P$. aeruginosa's invasiveness, tissue destruction and efficient 
colonization of ocular tissues (Gutierrez, 1972; Moore et al., 1995; Carter, 1999). Finally, the pigment pyocyanin may also contribute to tissue damage by inhibiting cellular oxygen uptake (Moore et al., 1995). Treatment of ocular surface infections where $P$. aeruginosa is isolated requires aggressive topical antibiotic therapy (Moore and Naisse, 2000).

However, over time it can be expected that ocular infections become less responsive to antibiotics due to the emergence of resistant bacterial strains. Therefore, it becomes important to implement a strategy for monitoring the emergence and spread of resistance. Antimicrobial susceptibility tests are an indispensable method to determine the most effective antibiotics for the treatment of eye infections.

The Kirby-Bauer disk diffusion test is the routine laboratory test used to determine antimicrobial susceptibility and it is crucial for veterinary ophthalmologists to provide an appropriate antimicrobial therapy (Moore et al., 1995).

Minimum inhibitory concentration (MIC) is the lowest concentration of an antimicrobial drug that will inhibit visible growth of a microorganism after incubation. Since it is a quantitative way to measure the susceptibility of an organism to an antimicrobial, MIC is considered an important tool for confirming resistance of microorganisms to a given antimicrobial agent (Andrews, 2001; CDC, 2002). This is particularly true for ocular surface infections, where a drug can be delivered directly to the site of infection at a high concentration compared to that of systemic intravenous administration (Levison and Levison, 2009).

Due to the aggressive nature of $P$. aeruginosa infections and the devastating consequences they can have on the eye, the lag time between diagnosis and antimicrobial susceptibility test results might enable significant and irreversible damage to be done to the eye prior to initiation of proper therapy. Epidemiological data of general susceptibility patterns may be helpful in certain situations such as when empiric rational therapy is indicated. The purpose of the present study was twofold: 1) investigate in vitro antibiotic susceptibilities by disc-diffusion of a panel of 11 antibiotics, and 2) investigate the minimal inhibitory concentrations of tobramycin and ciprofloxacin (two of the most commonly used topical antibiotics used for ocular surface infection) against naturally occurring $P$. aeruginosa ocular surface infections of dogs, cats, horses as well as two never before reported species, the Magellanic penguin and the brown bear.

\section{Specimen collection}

\section{Materials and Methods}

This study included sixteen $(\mathrm{n}=16)$ clinical isolates of $P$. aeruginosa from various species of animals presenting to the Comparative Ophthalmology Service at The Federal University of Paraná, Brazil with ocular surface infections (conjunctival, corneal or conjunctival and corneal). All the procedures using animals were conducted in accordance with the humane principles set forth in the ARVO Statement (Association for Research in Vision and Ophthalmology) for the Use of Animals in Ophthalmic and Vision Research and in accordance with UFPR's (Universidade Federal do Paraná) Animal Use Committee.

All animals were first examined for signs of ophthalmic or general clinical disease. A complete ocular examination, including slit lamp biomicroscopy (Hawk Eye; Dioptrix, L'Union, France), indirect ophthalmoscopy (Heine EN20-01 indirect ophthalmoscope; Heine Optotechnik, Herrsching, Germany), rebound tonometry (TonoVet tonometer; ICare Finland Oy, Helsinki, Finland), fluorescein staining (Drogavet; Curitiba-PR, Brazil), and Schirmer tear testing (Drogavet; Curitiba-PR, Brazil) was performed on each animal. Only animals presenting with signs of ocular surface infections without signs of uveitis, glaucoma, or systemic disease and with no history of having received systemic or topical ophthalmic antimicrobials in the preceding 30 days were included in the study.

\section{Bacterial identification}

A sterile cotton swab was used to gently sample the corneal and conjunctival surfaces of each infected eye. Swabs were then removed while taking care to avoid contact with eyelashes or skin of the eyelids. The swabs were kept in Stuart's transport medium, placed on ice and transported within 24 hours for microbiology culture. Swabs were plunged in BHI broth (brain heart infusion), an enrichment medium, for 24 hours at $37^{\circ} \mathrm{C}$. The enrichment cultures were then streaked onto 5\% Sheep Blood agar (Newprov®, Curitiba, Brazil).

Animals with signs of ocular surface infections in which $P$. aeruginosa was isolated were deemed to met all the inclusion criteria. Positive bacterial colonies were replicated in selective and differential media for Gram-negative bacteria (MacConkey agar and Brilliant Green agar). $P$. aeruginosa strains were confirmed by their Gram stain reaction, characteristic colonial morphology, oxidase production, motility and pyocyanin production (Quinn et al., 1994; Carter, 1999).

Subsequently, only the cases of ocular surface infections where $P$. aeruginosa was isolated were included. Different animal species that fit this criterion were: dogs (Canis familiaris) $(\mathrm{n}=10)$, horses (Equus caballus $)(\mathrm{n}=3)$, cat (Felis catus) $(\mathrm{n}=1)$, brown bear (Ursus arctos) $(\mathrm{n}=1)$ and a Magellanic penguin (Spnenicus megellanucus) $(\mathrm{n}=1)$. Ocular surface diseases diagnosed in these animals were: Corneal ulcers $(n=7) ; \quad$ Keratoconjunctivitis sicca $\quad(n=5)$; 
Blepharoconjunctivits $(n=4)$. Table 1 summarizes and further details the ocular surface diseases diagnosed in each animal species studied.

Table 1. List of animal species and ocular diseases from which $P$. aeruginosa was isolated.

\begin{tabular}{ccc}
\hline $\begin{array}{c}\text { Sample } \\
\text { identification }\end{array}$ & $\begin{array}{c}\text { Animal } \\
\text { species }\end{array}$ & Ocular diagnosis \\
\hline 1 & Dog & $\begin{array}{c}\text { Corneal ulcer } \\
\text { Oronasal fistula } \\
\text { + conjunctivitis }\end{array}$ \\
2 & Dog & KCS $^{*}$ \\
3 & Dog & Corneal ulcer \\
4 & Dog & Corneal ulcer \\
5 & Dog & KCS* \\
6 & Dog & KCS* \\
7 & Dog & Oronasal fistula \\
+ conjunctivitis \\
8 & Dog & KCS* \\
9 & Dog & KCS* \\
10 & Dog & Corneal ulcer \\
11 & Cat & Corneal ulcer \\
12 & Horse & Corneal ulcer \\
13 & Horse & Conjunctivitis \\
14 & Penguim ${ }^{1}$ & Conjunctivitis \\
15 & Brown Bear & Corneal ulcer \\
16 & Horse & \\
\hline
\end{tabular}

*keratoconjunctivitis sicca.

${ }^{1}$ Spnenicus megellanucus.

${ }^{2}$ Ursus arctos.

\section{Susceptibility tests}

Antimicrobial sensitivity of the isolated $P$. aeruginosa strains was determined by the disk-diffusion technique (also known as Kirby-Bauer method, one of the oldest approaches to antimicrobial susceptibility testing, in which is used Mueller-Hinton agar plates and it is used the direct colony suspension method to make a suspension of the organism in saline to the density of a McFarland 0.5 turbidity standard), in compliance with the National Committee for Clinical and Laboratory Standards (CLSI) (2013) criteria or European Committee on Antimicrobial Susceptibility Testing (EUCAST, 2013). Isolates whose antibiogram yielded intermediate results were considered resistant. Eleven (11) available antimicrobial discs (Newprov®, Curitiba, Brazil) were used: enrofloxacin $(10 \mu \mathrm{g})$, ciprofloxacin $(5 \mu \mathrm{g})$, norfloxacin $(10 \mu \mathrm{g})$, gatifloxacin $(10 \mu \mathrm{g})$, tobramycin $(10 \mu \mathrm{g})$, gentamicin $(10 \mu \mathrm{g})$, amikacin $(30 \mu \mathrm{g})$, streptomycin $(10 \mu \mathrm{g})$, neomycin $(30 \mu \mathrm{g})$, imipenem $(10 \mathrm{~g} \mu)$, polymyxin B (300U).
All the strains were tested to the minimal inhibitory concentration (MIC) test for tobramycin (antibiotic strip impregnated with the antibiotic and in which the concentration ranged from 0.016-128 $\mu \mathrm{g} / \mathrm{ml}$ ) and ciprofloxacin (antibiotic strip impregnated with the antibiotic and in which the concentration tested ranged from $0.002-32 \mu \mathrm{g} / \mathrm{ml}$ ), using a commercially available strip antibiotic test (E-test, AB Biodisk $\AA$, Sweden). Etest ${ }^{\circ}$ is a rapid and well-established method for antimicrobial resistance testing.

It consists of a predefined gradient of antibiotic concentrations on a plastic strip that carries a continuous concentration gradient of stabilized and dried drug. The intersection of the inhibitory zone with the strip is the MIC. The zone of inhibition was interpreted and classified as sensible, resistant and intermediate according to the manufacturer's manual (E-test, AB Biodisk®, Sweden). It was used MuellerHinton agar plates and used the direct colony suspension method to make a suspension of the organism in a saline solution to the density of a McFarland 0.5 turbidity standard. The MIC breakpoints were determined according to CLSI (2013) guidelines: $\mathrm{CIP}$, ciprofloxacin ( $\mathrm{S} \leq 1 ; \mathrm{I} 2 ; \mathrm{R} \geq 4)$; $\mathrm{TOB}$, tobramycin ( $\mathrm{S} \leq 4 ; \mathrm{I} 8 ; \mathrm{R} \geq 16$ ); intermediate results were considered resistant. $P$. aeruginosa ATCC 27853 was used as quality control.

\section{Results}

Typical signs encountered in the animals with septic ocular surface disease included blepharospasm, ocular discharge, conjunctival venous congestion and hyperemia, chemosis, low Schirmer tear test results, and corneal malacia, opacification, edema, neovascularization and ulceration. Imipenen was the only drug to which $100 \%$ of $P$. aeruginosa strains showed in vitro susceptibility in this study. A high susceptibility rate $(87.5 \%)$ was demonstrated to amikacin, followed by gentamicin, norfloxacin, gatifloxacin and polymyxin $(81.5 \%)$ and a low susceptibility rate to enrofloxacin $(25 \%)$. Results for all antibiotics tested are summarized in Table 2 and the breakpoints used to definy the strains as susceptiple or resistant were according CLSI (2013) guidelines.

Four strains of $P$. aeruginosa were resistant to ciprofloxacin: An isolate from a dog with corneal ulcer and oronasal fistula (sample 1), another isolate from a dog with keratoconjunctivitis sicca (sample 6), an isolate from cat with a corneal ulcer (sample 11), and an isolate from a horse with a deep corneal ulcer (sample 16). Five strains were resistant to tobramycin: The sample from a dog with corneal ulcer and oronasal fistula (sample 1), one from a dog with keratoconjunctivitis sicca (sample 6) three two from horses with corneal ulcers (sample 12 and 16 respectively), and one from a cat with corneal ulcer (case 11). 
Table 2. Antimicrobial susceptibility patterns of $P$. aeruginosa isolated from eyes of different species of animals.

\begin{tabular}{ccccccccccccccccccc}
\hline Drugs $^{\mathrm{a} / s a m p l e}$ & $1^{\mathrm{b}}$ & $2^{\mathrm{b}}$ & $3^{\mathrm{b}}$ & $4^{\mathrm{b}}$ & $5^{\mathrm{b}}$ & $6^{\mathrm{b}}$ & $7^{\mathrm{b}}$ & $8^{\mathrm{b}}$ & $9^{\mathrm{b}}$ & $10^{\mathrm{b}}$ & $11^{\mathrm{c}}$ & $12^{\mathrm{d}}$ & $13^{\mathrm{d}}$ & $14^{\mathrm{e}}$ & $15^{\mathrm{f}}$ & $16^{\mathrm{d}}$ & $\mathrm{S} \%$ & $\mathrm{R} \%$ \\
\hline ENO & $\mathrm{S}$ & $\mathrm{R}$ & $\mathrm{R}$ & $\mathrm{S}$ & $\mathrm{S}$ & $\mathrm{R}$ & $\mathrm{R}$ & $\mathrm{R}$ & $\mathrm{R}$ & $\mathrm{R}$ & $\mathrm{R}$ & $\mathrm{R}$ & $\mathrm{S}$ & $\mathrm{R}$ & $\mathrm{R}$ & $\mathrm{R}$ & 25 & 75 \\
CIP & $\mathrm{R}$ & $\mathrm{S}$ & $\mathrm{S}$ & $\mathrm{S}$ & $\mathrm{S}$ & $\mathrm{R}$ & $\mathrm{S}$ & $\mathrm{S}$ & $\mathrm{S}$ & $\mathrm{S}$ & $\mathrm{R}$ & $\mathrm{S}$ & $\mathrm{S}$ & $\mathrm{S}$ & $\mathrm{S}$ & $\mathrm{R}$ & 75 & 25 \\
NOR & $\mathrm{S}$ & $\mathrm{S}$ & $\mathrm{S}$ & $\mathrm{S}$ & $\mathrm{S}$ & $\mathrm{R}$ & $\mathrm{S}$ & $\mathrm{S}$ & $\mathrm{S}$ & $\mathrm{S}$ & $\mathrm{S}$ & $\mathrm{R}$ & $\mathrm{S}$ & $\mathrm{S}$ & $\mathrm{S}$ & $\mathrm{R}$ & 81.25 & 18.75 \\
$\mathrm{GAT}$ & $\mathrm{S}$ & $\mathrm{S}$ & $\mathrm{S}$ & $\mathrm{S}$ & $\mathrm{S}$ & $\mathrm{R}$ & $\mathrm{S}$ & $\mathrm{S}$ & $\mathrm{S}$ & $\mathrm{S}$ & $\mathrm{R}$ & $\mathrm{S}$ & $\mathrm{S}$ & $\mathrm{S}$ & $\mathrm{S}$ & $\mathrm{R}$ & 81.25 & 18.75 \\
TOB & $\mathrm{R}$ & $\mathrm{S}$ & $\mathrm{S}$ & $\mathrm{S}$ & $\mathrm{S}$ & $\mathrm{R}$ & $\mathrm{S}$ & $\mathrm{S}$ & $\mathrm{S}$ & $\mathrm{S}$ & $\mathrm{R}$ & $\mathrm{R}$ & $\mathrm{S}$ & $\mathrm{S}$ & $\mathrm{S}$ & $\mathrm{R}$ & 68.75 & 31.25 \\
GEN & $\mathrm{S}$ & $\mathrm{S}$ & $\mathrm{S}$ & $\mathrm{S}$ & $\mathrm{S}$ & $\mathrm{R}$ & $\mathrm{S}$ & $\mathrm{S}$ & $\mathrm{S}$ & $\mathrm{S}$ & $\mathrm{S}$ & $\mathrm{R}$ & $\mathrm{S}$ & $\mathrm{S}$ & $\mathrm{S}$ & $\mathrm{R}$ & 81.25 & 18.75 \\
AMI & $\mathrm{S}$ & $\mathrm{S}$ & $\mathrm{S}$ & $\mathrm{S}$ & $\mathrm{S}$ & $\mathrm{R}$ & $\mathrm{S}$ & $\mathrm{S}$ & $\mathrm{S}$ & $\mathrm{S}$ & $\mathrm{S}$ & $\mathrm{S}$ & $\mathrm{S}$ & $\mathrm{S}$ & $\mathrm{S}$ & $\mathrm{R}$ & 87.5 & 12.5 \\
EST & $\mathrm{S}$ & $\mathrm{S}$ & $\mathrm{S}$ & $\mathrm{R}$ & $\mathrm{S}$ & $\mathrm{R}$ & $\mathrm{S}$ & $\mathrm{R}$ & $\mathrm{S}$ & $\mathrm{S}$ & $\mathrm{S}$ & $\mathrm{R}$ & $\mathrm{S}$ & $\mathrm{S}$ & $\mathrm{R}$ & $\mathrm{R}$ & 62.5 & 37.5 \\
NEO & $\mathrm{S}$ & $\mathrm{R}$ & $\mathrm{R}$ & $\mathrm{S}$ & $\mathrm{S}$ & $\mathrm{R}$ & $\mathrm{R}$ & $\mathrm{R}$ & $\mathrm{S}$ & $\mathrm{S}$ & $\mathrm{S}$ & $\mathrm{R}$ & $\mathrm{S}$ & $\mathrm{S}$ & $\mathrm{S}$ & $\mathrm{R}$ & 56.25 & 43.75 \\
POL & $\mathrm{R}$ & $\mathrm{S}$ & $\mathrm{S}$ & $\mathrm{S}$ & $\mathrm{S}$ & $\mathrm{R}$ & $\mathrm{S}$ & $\mathrm{S}$ & $\mathrm{S}$ & $\mathrm{R}$ & $\mathrm{S}$ & $\mathrm{S}$ & $\mathrm{S}$ & $\mathrm{S}$ & $\mathrm{S}$ & $\mathrm{S}$ & 81.25 & 18.75 \\
$\mathrm{IMI}$ & $\mathrm{S}$ & $\mathrm{S}$ & $\mathrm{S}$ & $\mathrm{S}$ & $\mathrm{S}$ & $\mathrm{S}$ & $\mathrm{S}$ & $\mathrm{S}$ & $\mathrm{S}$ & $\mathrm{S}$ & $\mathrm{S}$ & $\mathrm{S}$ & $\mathrm{S}$ & $\mathrm{S}$ & $\mathrm{S}$ & $\mathrm{S}$ & 100 & 0 \\
\hline
\end{tabular}

a. Drugs: ENO: enrofloxacin; CIP: ciprofloxacin; NOR: norfloxacin; GAT: gatifloxacin; TOB: tobramycin; GEN: gentamicin; AMI: amikacin; EST: streptomycin; NEO: neomycin; POL: polymyxin B; IMI: imipenem. Susceptibilities: (S): susceptible; (R): resistant.

(b): Strain isolated from dog.

(c): Strain isolated from cat.

(d): Strain isolated from horse.

(e): Strain isolated from penguin.

(f): Strain isolated from black bear.

Table 3. Minimum inhibitory concentration (MIC) of 16 strains of $P$. aeruginosa recovered from eyes of different species of animals.

\begin{tabular}{ccccc}
\hline Sample & CIP $(\mu \mathrm{g} / \mathrm{mL})^{\mathrm{a}}$ & Sus. & TOB $(\mu \mathrm{g} / \mathrm{mL})^{\mathrm{a}}$ & Sus. \\
\hline $1^{\mathrm{b}}$ & 4.00 & $\mathrm{R}$ & 8.00 & $\mathrm{R}$ \\
$2^{\mathrm{b}}$ & 0.19 & $\mathrm{~S}$ & 2.00 & $\mathrm{~S}$ \\
$3^{\mathrm{b}}$ & 0.13 & $\mathrm{~S}$ & 2.00 & $\mathrm{~S}$ \\
$4^{\mathrm{b}}$ & 0.094 & $\mathrm{~S}$ & 1.50 & $\mathrm{~S}$ \\
$5^{\mathrm{b}}$ & 0.25 & $\mathrm{~S}$ & 0.25 & $\mathrm{~S}$ \\
$6^{\mathrm{b}}$ & 12.00 & $\mathrm{R}$ & $\leq 256$ & $\mathrm{R}$ \\
$7^{\mathrm{b}}$ & 0.19 & $\mathrm{~S}$ & 3.00 & $\mathrm{~S}$ \\
$8^{\mathrm{b}}$ & 0.38 & $\mathrm{~S}$ & 4.00 & $\mathrm{~S}$ \\
$9^{\mathrm{b}}$ & 0.094 & $\mathrm{~S}$ & 1.00 & $\mathrm{~S}$ \\
$10^{\mathrm{b}}$ & 0.094 & $\mathrm{~S}$ & 1.00 & $\mathrm{~S}$ \\
$11^{\mathrm{c}}$ & 2.00 & $\mathrm{R}$ & 32.00 & $\mathrm{R}$ \\
$12^{\mathrm{d}}$ & 0.094 & $\mathrm{~S}$ & 1.50 & $\mathrm{~S}$ \\
$13^{\mathrm{d}}$ & 0.094 & $\mathrm{~S}$ & 1.00 & $\mathrm{~S}$ \\
$14^{\mathrm{e}}$ & 0.094 & $\mathrm{~S}$ & 1.50 & $\mathrm{~S}$ \\
$15^{\mathrm{f}}$ & 0.094 & $\mathrm{~S}$ & 1.00 & $\mathrm{~S}$ \\
$16^{\mathrm{d}}$ & $\leq 32$ & $\mathrm{R}$ & $\leq 256$ & $\mathrm{R}$
\end{tabular}

a. Drugs: CIP, ciprofloxacin ( $\leq \leq 1 ; \mathrm{I} 2 ; \mathrm{R} \geq 4$ ); TOB, tobramycin ( $\leq 4$; I 8; R $\geq 16$ ). Sus: Susceptibilities; S: susceptible; R: resistant.

(b): Strain isolated from dog.

(c): Strain isolated from cat.

(d): Strain isolated from horse.

(e): Strain isolated from penguin.

(f): Strain isolated from black bear.
Table 3 summarizes the MIC $(\mu \mathrm{g} / \mathrm{ml})$ results to ciprofloxacin and tobramycin of all 16 strains of $P$. aeruginosa. According to the CLSI (2013) MIC breakpoints, four isolates presented MIC values that demonstrated resistance to ciprofloxacin. Four isolates were resistant to tobramycin (same were resistant to ciprofloxacin). The four resistant strains were recovered from a dog (corneal ulcer; case 1), dog (KCS; case 6), a cat (corneal ulcer, case 11) and a horse (corneal ulcer, case 16).

In general MIC values for tobramycin were higher than for ciprofloxacin for all strains of $P$. aeruginosa evaluated. MIC values for ciprofloxacin varied from $0.13 \mu \mathrm{g} / \mathrm{ml}$ to $32 \mu \mathrm{g} / \mathrm{ml}$ and the average MIC value was $3.24 \pm \mu \mathrm{g} / \mathrm{ml}$. MIC ${ }_{90}$ of ciprofloxacin was $3 \mu \mathrm{g} / \mathrm{ml}$ and $\mathrm{MIC}_{50}$ was $0.94 \mu \mathrm{g} / \mathrm{ml}$. MIC values for tobramycin varied from $0.25 \mu \mathrm{g} / \mathrm{ml}$ to $256 \mu \mathrm{g} / \mathrm{ml}$. The average MIC value was $35.76 \mu \mathrm{g} / \mathrm{ml}$. The $\mathrm{MIC}_{90}$ was $48 \mu \mathrm{g} / \mathrm{ml}$ and the $\mathrm{MIC}_{50}$ was $1.50 \mu \mathrm{g} / \mathrm{ml}$.

\section{Discussion}

Animals, especially dogs, are well known naturallyoccurring $P$. aeruginosa ulcerative keratitis models. The infection is considered appropriate for comparative investigations since this bacterial agent in canine infections is congruent with the classic genotypephenotype pattern reported for human corneal isolates (Ledbetter et al., 2009).

$P$. aeruginosa strains isolated from ocular infections have a particularly important role when prior ocular surface disease provides an opportunity for colonization and stabilization of an eye infection. 
These conditions include keratoconjunctivitis sicca, corneal ulcers, chronic conjunctivitis and dental problems combined with infraorbital fistulas (Moore $e t$ al., 1995; Ledbetter et al., 2009; Wada et al., 2010). The majority of these primary conditions were observed in the eyes of subjects in the present study (Table 1). Treatment with antibiotics effective against Gram-negative bacteria is usually successful. However, in some cases emergence of strains resistant to available antibiotics makes treatment difficult and poses as a real threat to an eye (Wada et al., 2010). A low in vitro susceptibility rate $(25 \%)$ was observed for enrofloxacin against $P$. aeruginosa isolated from ocular tissues. This result was also observed by other authors while researching strains of $P$. aeruginosa from cases of keratitis in cats and dogs (Lin and PetersenJones, 2007, 2008). Conversely, the in vitro action of norfloxacin against $P$. aeruginosa was considered good since only three strains were resistant, one from a dog and two from horses. Another study investigating strains from dogs with septic keratitis also found good susceptibility rates for this drug, since only one strain (1/27) was resistant (Lin and Petersen-Jones, 2007). Ciprofloxacin demonstrated a satisfactory degree of in vitro activity against $P$. aeruginosa (75\% susceptible strains) and four resistant strains were detected. Lin and Petersen-Jones (2007) encountered high in vitro susceptibility of this drug against $P$. aeruginosa, where $95 \%$ of the isolates from dogs with corneal ulcers were susceptible. In another investigation (Lin and PetersenJones, 2008), $P$. aeruginosa isolates from ulcerative keratitis of cats showed an even better result, with $100 \%$ of the strains being susceptible to ciprofloxacin. The fourth-generation fluorquinolone tested here, gatifloxacin, also showed a good in vitro susceptibility against $P$. aeruginosa, since three strains demonstrated resistance $(81.5 \%)$. Another report (Ledbetter et al., 2007) found $100 \%$ of strains from ulcerative keratitis in dogs susceptible for gatifloxacin. Compared with earlier generations, fourth-generation fluoroquinolones have an expanded spectrum of activity against Grampositive bacteria, anaerobic bacteria, mycobacteria, and species of Chlamydia, Chlamydophila, Mycoplasma, and Ureaplasma (Moore et al., 1995; Kowalski et al, 2003; Ledbetter et al., 2007). Gram-negative bacterial spectrum of the third- and fourth-generation fluoroquinolones is preserved. However, compared with earlier generations (especially ciprofloxacin), they are less active in vitro against many Gram-negative bacteria, including $P$. aeruginosa (Kowalski et al, 2003; Ledbetter et al., 2007). Therefore, even though there is a mass marketing pressure for clinicians to prescribe newer antibiotic drugs it is noteworthy that according to the literature (Jensen et al., 2005) and the results presented in this study, there was no difference between the in vitro activity of gatifloxacin (fourth generation) and ciprofloxacin (second generation fluoroquinolone) against strains of $P$. aeruginosa; all strains that were resistant to ciprofloxacin, were also resistant to gatifloxacin.

Four pseudomonas strains isolated in this study demonstrated resistance to at least one of the aminoglycosides tested here. A total of $87.5 \%$ were susceptible to amikacin, $81.5 \%$ to gentamicin and $68.7 \%$ to tobramycin. Hariharan et al. (1995) found that $100 \%$ of pseudomonas strains from dogs were susceptible to tobramycin and amikacin, and $95 \%$ to gentamicin. Lin and Petersen-Jones (2008) found high susceptibility in vitro rates for amikacin (100\%), tobramycin $(80 \%)$ and gentamicin $(75 \%)$ isolated from dogs with keratitis. Our results corroborate previous investigations of $P$. aeruginosa isolates indicating that these drugs are still effective. Aminoglycosides are an important antibiotic group available in veterinary ophthalmic formulations. When compared with another bacterial genera frequently isolated from animal eyes, e.g. Staphylococcus, gentimicin and tobramycin are not very effective $(47.5 \%$ of the strains were resistant to gentamicin and $65 \%$ were resistant to tobramycin) (Varges et al., 2009). This confirms the importance of identifying the specific pathogen in a given bacterial ocular surface disease and determining its respective sensitivity pattern. The use of topical amikacin has been suggested as a better empiric alternative to gentamicin or tobramycin (Hariharan et al., 1995). In our results, two strains that were resistant to tobramycin were susceptible for amikacin (cases $\mathrm{n}^{\circ} 11$ and 12) and two strains were resistant to all aminoglycosides tested (cases $n^{\circ} 6$ and 16). The appearance of strains resistant to amikacin is of some concern since this drug is one of the most useful agents for treatment of severe $P$. aeruginosa infections (Hariharan et al., 1995).

In this investigation, $56.5 \%$ of the strains were susceptible to neomycin, similar to the susceptibility reported in another study of $P$. aeruginosa isolates from feline ulcerative keratitis $(63 \%)$ (Lin and PetersenJones, 2008). Neomycin is commonly prescribed in combination with bacitracin and polymyxin $\mathrm{B}$ for topical therapy of eye infections in triple antibiotic formulations. Triple antibiotic formulations maximize the spectrum of antibacterial activity against both Gram-positive and Gram-negative bacteria. Pseudomonas spp. is often resistant to neomycin, but polymixin B is rapidly bactericidal against Gramnegative bacteria, including $P$. aeruginosa (Lima Filho and Batistuzzo, 2006). In our study, $81 \%$ of $P$. aeruginosa were susceptible in vitro to polymixin $\mathrm{B}$. However, previous studies have conflicting results, ranging from $100 \%$ susceptibility of veterinary isolates (Hariharan et al., 1995) to susceptibility rates as low as $40 \%$ (Ledbetter et al., 2009). We also observed that nearly all strains that were resistant neomycin were 
susceptible to polymixin B, or vice-versa. Thus, our in vitro results corroborate the clinical recommendation for this triple antibiotic combination to be used as a first choice option for treatment of ocular surface $P$. aeruginosa infections (Maggs, 2008).

No isolates tested in this study were resistant to imipenem. The carbapenems antibiotics are commonly used in human multi-resistant pseudomonas infections. The lack of apparent resistance of $P$. aeruginosa strains to imipenem should be highlighted, especially when compared to those findings obtained from cases of human $P$. aeruginosa isolates, in which the in vitro resistance can reach 4\% (Mohammadpour et al., 2011) to $40 \%$ (Fernandes et al., 2015). Although this drug is rarely used in veterinary medicine and is not approved for use in animals by the Food and Drug Administration, veterinarians can legally prescribe imipenem as an extra-label drug for ocular infections consisting of multi-resistant strains of $P$. aeruginosa. Although use of intravenous imipenem preparations topically on the eye has been suggested for ocular infections with multi-resistant $P$. aeruginosa strains, the high price, instability of imipenem solutions [it should be used within 48 hours and kept under refrigeration (Lima Filho and Batistuzzo, 2006)], and debate about reservation for human use make it a rare treatment choice.

Based on this study, the best in vitro activities against $P$. aeruginosa isolated from animal's eyes could be ranked as 1: imipenem, 2: amikacin, 3: gatifloxacin, norfloxacin, gentamicin or polymyxin. Imipenem and amikacin eye drops are only available in extemporaneous compounding formulations. Gatifloxacin, norfloxacin, gentamicin and polymyxin are commercially available in the form of eye drops in most countries.

Even with a small sample size of 16 positive $P$. aeruginosa cultures, this work presents interesting data. Notice that diagnoses include conjunctivitis and keratoconjunctivitis sicca, which are normally not primarily caused by Pseudomonas, but high resistant strains were isolated, could complicate or delay the disease resolution.

This investigation also determined the MIC values of two important antibiotics commercially available in the form of eye drops and commonly used in veterinary and medical ophthalmology: ciprofloxacin and tobramycin. In vitro resistance breakpoints are based on antibiotic concentrations in the blood (CLSI, 2013). However, because ocular antibiotics can reach higher concentrations, this breakpoint does not truly represent bacterial resistance in the eye. Ocular antibiotics will most likely have a higher resistance breakpoint value than systemic antibiotics. For example, a $1 \%$ drop with a concentration of $10 \mu \mathrm{g} / \mathrm{mL}$ results in a concentration of $10.000 \mu \mathrm{g} / \mathrm{mL}$ on the eye. Alternatively, in the serum, tissues, or blood, the level may only be 10 $\mu \mathrm{g} / \mathrm{mL}$ when the same drug is administered orally (Mah, 2003). Therefore, bacteria identified as resistant elsewhere in the body (e.g. lung) may respond differently if located in the eye and are exposed to topical antibiotic. Studies conducted by Kaye et al. (2009) showed that topical administration of an antimicrobial to the cornea may achieve a different concentration and bioavailability in the tissue than the serum levels. In the treatment of bacterial keratitis, the MIC values are an important measure for evaluating the potential effectiveness of topically applied antimicrobials (Sueke et al., 2010).

Both tobramycin and ciprofloxacin formulated as eye drops have a concentration of $3 \mathrm{mg} / \mathrm{mL}$ in commercially available solutions (Peiffer and Stowe, 1981; Viana, 2007). If one drop (approximately $0.05 \mathrm{~mL}$ as commercially droppers delivery a 25 a $50 \mu \mathrm{L} /$ drop of solution or suspension), is instilled into the eye, the solution maintains a good antibiotic concentration $(0.15 \mathrm{mg})$. Knowing that the conjunctival fornix of the eye will hold only one drop (Peiffer and Stowe, 1981) (which means $0.05 \mathrm{~mL}$ ) and only 10 to $25 \mu \mathrm{L}$ of drug are retained in the conjunctival fornix and tear film (Peiffer and Stowe, 1981; Viana, 2007), the concentration of the drugs still will be at $75 \mu \mathrm{g}$.

The MIC values found for ciprofloxacin in this study ranged from 0.094 to $32 \mu / \mathrm{mL}$, so, for this drug, the amount present in the conjunctival fornix, exceed the MIC of the strains tested. For tobramycin, the MIC ranged from 0.25 to $256 \mu \mathrm{g} / \mathrm{mL}$. One MIC isolate tested was $48 \mu \mathrm{g} / \mathrm{mL}$ (case $\mathrm{n}^{\circ} 11$ ) and two others (cases $n^{\circ} 6$ and 16) exceed the MIC ( $256 \mu \mathrm{g} / \mathrm{mL})$ of this antibiotic, and for this isolate, the use of eye drops might not be medically effective. A study conducted in ophthalmology centers in the United Kingdom demonstrated the MICs for P. aeruginosa isolated from human keratitis ranged from 0.016 to $6.000 \mathrm{mg} / \mathrm{L}$ (Sueke et al., 2010).

The average concentration of antibiotics in tears may vary. For ciprofloxacin ( $0.3 \%$ ophthalmic solution) 4 hours after instillation, tear concentration becomes 16 $\mu \mathrm{g} / \mathrm{mL}$ in human beigns (Limberg and Buggé, 1994) and $36.25 \mu / \mathrm{mL}$ for horses (Hendrix et al., 2007). Considering that the MIC of the strains tested in this study did not exceed $12 \mu \mathrm{g} / \mathrm{mL}$, the concentration of this drug in tears within four hours is still most likely higher, so instillation of one drop of ciprofloxacin is effective if repeated every four hours.

One study (Tang-Liu et al., 1994) showed that 4 hours after instillation, tobramycin has an average concentration of $8 \mu \mathrm{g} / \mathrm{mL}$ in human tears. Therefore, this concentration would still be effective against most strains tested in this study, since most strains had an MIC of $1.00 \mu \mathrm{g} / \mathrm{mL}$. However, four strains obtained higher MICs $(8 \mu \mathrm{g} / \mathrm{mL}, 48 \mu \mathrm{g} / \mathrm{mL}$ and two isolated with 
$256 \mu \mathrm{g} / \mathrm{mL})$. These MICs suggest poor response to treatment in vivo with tobramycin considering the possible MICs that can be achieved in the most common eye drop treatment protocols. Therefore, it is recommended to increase the frequency of administering tobramycin from every four to approximately every two hours.

MIC at the site of a $P$. aeruginosa ocular surface infection must reach high concentrations in order to be effective. The evaluation of $P$. aeruginosa susceptibility by microbiology laboratories is typically made with reference to concentrations in human serum. However, concentrations of antibiotics obtained from the ocular surface by local application of eye drops or ointments are higher, and it is important to determine the MIC to better assess the antibiotic susceptibility of specific bacterial strains isolated from ocular surface infections.

Our study revealed that the antimicrobials with the best in vitro actions against $P$. aeruginosa isolated from the eyes of selected animals from Brazil were 1: imipenem, 2: amikacin, 3: gatifloxacin, norfloxacin, gentamicin or polymyxin. This study also showed that commercially available concentrations of ciprofloxacin eye drops used for local treatment $(3 \mathrm{mg} / \mathrm{ml}$ ) was effective against all strains tested in this study if applied up to 4 hours after instillation. For tobramycin eye drops as commercially presentation the concentrations of $3 \mathrm{mg} / \mathrm{ml}$, however, cannot reach an ideal MIC for some resistant strains with. Thus for ocular surface infections with $P$. aeruginosa when using tobramycin the ideal recommendation would be to either to use eye drops with higher concentrations or decrease the frequency intervals from four hours to a minimum of every two hours.

\section{Conflict of interest}

No competing financial interests exist.

\section{References}

Akpek, E.K. and Gottsch, J.D. 2003. Immune defense at the ocular surface. Eye (Lond). 17, 949-956.

Andrews, J.M. 2001. Determination of minimum inhibitory concentrations. J. Antimicro. Chemoth. 48, 5-16.

Carter, G.R. 1999. Pseudomonas. In Carter, G.R.: Fundamentos em Bacteriologia e Micologia Veterinária, 1ed, Ed Roca, São Paulo.

CDC. 2002. Addressing the problem of antimicrobial resistance. National Center for Infectious Disease. Target Area Booklet CDC.

Clinical and Laboratory Standards Institute (CLSI). 2013. Performance Standards for Antimicrobial Susceptibility Testing: Twenty-third Informational Supplement M100-S23. LSI, Wayne, PA, USA.

European Committee on Antimicrobial Susceptibility Testing (EUCAST). 2013. EUCAST guidelines for detection of resistance mechanisms and specific resistances of clinical and/or epidemiological importance. EUCAST, Basel, Switzerland: http://www.eucast.org/clinical_breakpoints.

Fernandes, M., Vira, D., Medikonda, R. and Kumar, N. 2015. Extensively and pan-drug resistant Pseudomonas aeruginosa keratitis: clinical features, risk factors, and outcome. Graefes. Arch. Clin. Exp. Ophthalmol. 254, 315-322.

Gutierrez, E.H. 1972. Bacterial infections of the eye. In: D.Locatcher-Khorazo and B.C. Seegal. (ed), Microbiology of the eye. The C.V. Mosby Co., St. Louis, pp: 69-70.

Hariharan, H., Mcphee, L., Heaney, S. and Bryenton, J. 1995. Antimicrobial drug susceptibility of clinical isolates of Pseudomonas aeruginosa. Can. Vet. J. 36, 166-168.

Hendrix, D.V.H., Stuffle, J.L. and Cox, S.K. 2007. Pharmacokinetics of topically applied ciprofloxacin in equine tears. Vet. Ophthtalmol. 10, 344-347.

Jensen, H., Zerouala, C., Carrier, M. and Short, B. 2005. Comparison of ophthalmic gatifloxacin $0.3 \%$ and ciprofloxacin $0.3 \%$ in healing of corneal ulcers associated with Pseudomonas aeruginosa-induced ulcerative keratitis in rabbits. J. Ocul. Pharmacol. Ther. 21, 36-43.

Kaye, S.B., Neal, T., Nicholson, S., Szkurlat, J., Bamber, S., Baddon, A.C., Anderson, S., Seddon, K., Dwyer, N., Lovering, A.M. and Smith, G. 2009. Concentration and bioavailability of ciprofloxacin and teicoplanin in the cornea. Invest. Ophthalmol. Vis. Sci. 50, 3176-3184.

Kowalski, R.P., Dhaliwal, D.K., Karenchak, L.M., Romanowski, E.G., Mah, F.S., Ritterband, D.C. and Gordon, Y.J.2003. Gatifloxacin and moxifloxacin: an in vitro susceptibility comparison to levofloxacin, ciprofloxacin, and ofloxacin using bacterial keratitis isolates. Am. J. Ophthalmol. 136, 500-505.

Ledbetter, E.C., Hendricks, L.M., Riis, R.C. and Scarlett, J. 2007. In vitro fluoroquinolone susceptibility of Pseudomonas aeruginosa isolates from dogs with ulcerative keratitis. Am. J. Vet. Res. 68, 638-642.

Ledbetter, E.G., Mun, J.J., Kowbel, D. and Fleiszig, S.M.J. 2009. Pathogenic phenotype and genotype of Pseudomonas aeruginosa isolates from spontaneous canine ocular infections. Investig. Ophthalmol. Visual. Sci. 50, 729-736.

Levison, M.E. and Levison, J.H. 2009. Pharmacokinetics and Pharmacodynamics of Antibacterial Agents. Infect. Dis. Clin. North Am. 23, 791-815.

Lima Filho, A.A.S. and Batistuzzo, J.A.O. 2006. Formulações Magistrais em oftalmologia, Cultura Médica, Rio de Janeiro, Brasil. 
Limberg, M. and Buggé, C. 1994. Tear concentrations of topically applied ciprofloxacin. Cornea 13, 496499.

Lin, C.T. and Petersen-Jones, S.M. 2007. Antibiotic susceptibility of bacterial isolates from corneal ulcers of dogs in Taiwan. J. Small Anim. Pract. 48, 271-274.

Lin, C.T. and Petersen-Jones, S.M. 2008. Antibiotic susceptibility of bacteria isolated from cats with ulcerative keratitis in Taiwan. J. Small Anim. Pract. 49, 80-83.

Maggs, D.J. 2008. Cornea and sclera. In: Maggs, D.J., Miller, P.E. and Ofri, R. Slatter's Fundamentals of Veterinary Ophthalmology $4^{\text {th }}$ Ed. Saunders Elsevier, St Louis. pp: 175-202.

Mah, F.S. 2003. New antibiotics for bacterial infections. Ophthalmol. Clin. North Am. 16, 11-27.

Mannis, M.J. and Smolin, G. 1996. Natural defense mechanisms of the ocular surface. In: Pepose, J.S., Holland, G.N. and Wilhelmeus, K.R. (eds). Ocular Infection and Immunity. Mosby: St Louis, MO, pp: 185-190.

Mayo, M.S., Cook, W.L., Schlitzer, R.L., Ward, M.A., Wilson, L.A. and Ahearn, D.G. 1986. Antibiograms, serotypes, and plasmid profile of Pseudomonas aeruginosa associated with corneal ulcers and contact lens wear. J. Clinic. Microbiol. 24, 372-376.

Mohammadpour, M., Mohajernezhadfard, Z., Khodabande, A. and Vahedi, P. 2011. Antibiotic Susceptibility Patterns of Pseudomonas Corneal Ulcers in Contact Lens Wearers. Middle East African J. Ophthalmol. 18, 228-231.

Moore, C.P., Collins, B.K. and Fales, W.H. 1995.
Antibacterial susceptibility patterns for microbial isolates associated with infectious keratitis in horses: 63 cases (1986-1994). J. Am. Vet. Med. Assoc. 207, 928-933.

Moore, C.P. and Naisse, M.P. 2000. Clinical Microbiology. In: Gellat, K.N. Veterinary Ophthalmology. $3^{\text {rd }}$ Ed, pp: 259-289.

Peiffer, R.L. and Stowe, C.M. 1981. Veterinary ophthalmic pharmacology. In: Gelatt, K.N. ed. Veterinary Ophthalmology. $2^{\text {nd }}$ ed. Philadelphia: Lea \& Febiger, pp: 160-205.

Quinn, P.J., Carter, M.E., Markey, B. and Marter, G.R. 1994. Pseudomonas species. In: Ibid. (Eds), Clinical Veterinary Microbiology. Wolfe, London, pp: 237-242.

Sueke, H., Kaye, S. and Neal, T. 2010. Minimum inhibitory concentrations of standard and novel antimicrobials for isolates from bacterial keratitis," Invest. Ophthalmol. Vis. Sci. 51, 2519-2524.

Tang-Liu, D.D.S., Schob, D.L., Usansky, J. and Gordon, Y.J. 1994. Comparative tear concentrations over time of ofloxacin and tobramycin in human eyes. Clin. Pharmacol. Therapeutics 55, 284-293.

Varges, R., Penna, B., Martins, G., Martins, R. and Lilenbaum, W. 2009. Antimicrobial susceptibility of Staphylococcus isolated from naturally occurring canine external ocular diseases. Vet. Ophthalmol. 12, 216-220.

Viana, F.A.B. 2007. Guia terapêutico veterinário. 2ed., Editora CEM, Lagoa Santa.

Wada, S., Hobo, S. and Niwa, H. 2010. Ulcerative keratitis in thoroughbred racehorses in Japan from 1997 to 2008. Vet. Ophthalmol. 13, 99-105. 